\title{
1968, REVOLUÇÃO POLÍTICA E REVOLUÇÃO DOS COSTUMES: HERBERT DANIEL, ESTUDANTE, GUERRILHEIRO E EXILADO
}

Johnnatan Monteiro ${ }^{1}$

\begin{abstract}
RESUMO: Em quase cinco décadas, os movimentos de contestação social ocorridos em 1968 continuam sendo periodicamente revisitados. No contexto brasileiro, podemos observar que reconstruções memorialísticas das transformações comportamentais tem ajudado a conciliar esferas sociais que se acomodaram à ditadura civil-militar instaurada em 1964, com a memória dos grupos de jovens estudantes, artistas, intelectuais e trabalhadores que de alguma forma enfrentaram as brutalidades do regime. Uso do passado que silencia a importância das lutas de oposição política e revolucionária em contrapartida à exaltação das mudanças comportamentais. Assim para analisar as margens de negociação existentes entre as esquerdas que compuseram a "geração 68 brasileira" no que diz respeito a como lidavam com as relações de gênero e as sexualidades, será explorada a trajetória do militante estudantil, guerrilheiro e exilado político Herbert Daniel e como sua homossexualidade foi vivida no decorrer deste processo.
\end{abstract}

Palavras-chave: Geração 68. Ditadura Civil-Militar. Relações de Gênero

\section{8, POLITICAL REVOLUTION AND CUSTOMS REVOLUTION: HERBERT}

\section{DANIEL, STUDENT, GUERRILLA AND EXILE}

ABSTRACT: In almost five decades, social protest movements in 1968 continue to be periodically revisited. In the Brazilian context, we can observe that memorialistic reconstructions of behavioral transformations have helped to reconcile social spheres that were adapted to the civil-military dictatorship established in 1964, with the memory of groups of young students, artists, intellectuals and workers who somehow brutalities of the regime. Use of the past that silences the importance of the struggles of political and revolutionary

\footnotetext{
${ }^{1}$ Mestre pelo Programa de Pós-Graduação em Historia da Universidade Federal Fluminense, professor da rede estadual do Rio de Janeiro. Foi aluno do curso de graduação em História na mesma universidade. Endereço eletrônico: johnnatanbias@gmail.com.
} 
opposition in counterpart to the exaltation of behavioral changes. Thus, in order to analyze the negotiating margins that exist between the lefts that composed the "Brazilian 68 generation" as regards how they deal with gender relations and sexualities, the trajectory of the student militant, guerrilla and political exile Herbert Daniel will be explored. how his homosexuality was lived through this process.

Keywords: Generation 68. Civil-Military Dictatorship. Gender Relations

\section{8, REVOLUCIÓN POLÍTICA Y REVOLUCIÓN DE LAS COSTUMBRES: HERBERT DANIEL, ESTUDIANTE, GUERRILLERO Y EXILIADO}

RESUMEN: En cinco décadas, los movimientos de respuesta social que ocurrieron en 1968 continuaron siendo periódicamente revisitados. En el contexto brasileño, podemos ver que las reconstrucciones conmemorativas Transformaciones de las conductas han ayudado a reconciliar las zonas sociales que se acomodaron a la dictadura civil-militar instituido en 1964 con Memoria dos grupos de jóvenes estudiantiles, artistas, intelectuales y trabajadores que alguna forma se enfrentaron como brutalidades del régimen. Uso del pasado que silencia la importancia de la oposición política y de los revolucionarios en contraposición a la exaltación de las alteraciones comportamentales. En el caso de las mujeres, las mujeres y las mujeres, en el caso de las mujeres, no se sienten satisfechas. no procede de este proceso.

Palavras Clave: Generación 68. Dictadura Civil-Militar. Relaciones de Género.

Cerca de quarenta países, no turbulento ano de 1968, viveram movimentos de contestação social, cujos jovens, em sua maioria estudantes, constituíram os principais atores envolvidos (REIS FILHO, 2008, p. 27). De forma geral, bandeiras anti-imperialistas, com críticas contundentes à guerra do Vietnã; anticapitalistas, questionando a inserção da classe operária na lógica do trabalho voltado para o consumo; e de crítica ao socialismo real, em suas lógicas burocráticas e autoritárias; relativamente comuns em muitos países, permitiram que alguns autores colocassem estes movimentos como partes de um mesmo processo de contestação social que se desenvolveu mundialmente naquele momento (GARCIA, 1999, pp. 10-14). No entanto, é preciso pontuar que em cada país, para além das citadas bandeiras unificadoras, tais movimentos possuíam reivindicações e formas de luta específicas ligadas às demandas cotidianas, às conjunturas políticas e aos contextos sociais que estavam inseridos. Tal ressalva se faz necessária, na medida em que falas a partir do presente e suas consequentes determinações sob a memória (ROUSSO, 1996, p. 98) acabam por resumir os movimentos de contestação social ocorridos internacionalmente em 1968, em certos aspectos, de forma bastante homogênea. Assim em um amplo contexto de reapropriações e disputas, 
que envolvem vários grupos interessados na recuperação do processo desenvolvido em 1968 no Brasil, a questão da revolução dos costumes e comportamentos, recorrentemente relacionada às agitações sociais ocorridas pelo mundo ao longo deste ano e aos seus desdobramentos, se encaixa enquanto um típico exemplo de uma lógica da memória que constrói representações unificadas do passado (ROUSSO, 1996, p. 96).

Em meio às comemorações realizadas década a década, não apenas a academia, mas também grupos de esquerda de diversos países promovem reatualizações sobre a importância de 1968 e suas consequências enquanto acontecimento. Assim, o amplo e variado processo de questionamento social que saltou aos olhos naquele ano, tem se integrado a cultura política presente em muitos partidos, sindicatos e movimentos sociais de esquerda. Nacionalmente é comum verificar a presença das transformações políticas e culturais advindas dos processos de contestação social de 1968 na memória do movimento estudantil e na memória da luta armada que, cada qual a seu modo, mas com interseções entre si, enfrentaram a ditadura civilmilitar brasileira. Como também podemos verificar que a memória dos acontecimentos de 1968 e seus desdobramentos ainda são partes vivas das histórias pessoais, políticas e intelectuais dos militantes que aderiram aos movimentos de oposição ao regime autoritário vigente em nosso país. Assim, as manifestações coletivas e individuais da memória social a partir das narrativas de grupos e pessoas que se opuseram politicamente a ditadura civilmilitar, na qual os acontecimentos e transformações de 1968 aparecem significativamente como ponto de convergência de muitas lembranças, representando para as esquerdas brasileiras um simbólico ponto de apoio para sua identidade.

Também os meios de comunicação formularam acerca dos anos comemorativos versões dos acontecimentos de 1968 e seus impactos na vida social. Em geral, uma vasta gama de produções literárias, fílmicas e televisivas são realizadas alcançando um público considerável e funcionando como referências significativas do olhar de sociedades do presente para o passado. No caso brasileiro, este olhar envolve um processo conciliatório em relação a um passado traumático. Pois relembrar 1968 no Brasil, entre outras perspectivas, se relaciona diretamente a recuperação, em média a cada dez anos, da memória da luta radical de um grupo dentro de uma simbólica geração, composto por alguns jovens estudantes urbanos de classe média que enfrentaram o terrorismo de Estado praticado pela ditadura civil-militar, na tentativa de derrubar o regime e de promover a revolução socialista através da luta armada.

Ao longo das décadas, verificamos o desenvolvimento de tendências que recuperam os movimentos de 1968 como comprometidos até a medula com a profunda renovação dos 
costumes. Porém, uma analise historiográfica mais minuciosa nos indica que, em determinados casos, as evidências de tal perspectiva não se apresentam de forma tão clara. Essa constatação nos leva a pensar até que ponto as transformações comportamentais que ocorreram ao longo do tempo não estão ligadas a complexas operações memorialísticas que devem ser interpretadas.

A compreensão de 1968 enquanto processo e seus desdobramentos esbarram logo de inicio no entrelaçar de muitas memórias que dificultam a existência de um consenso sobre seu significado histórico. No entanto, ao nos debruçarmos sobre o diversificado conjunto de fontes composto por jornais, livros, peças de teatro, filmes documentários, filmes de ficção e séries de TV, produzidos por ocasião das proximidades dos aniversários redondos de 1968: 1978, 1988, 1998, 2008 e 2018, e ao buscarmos referências nas pesquisas historiográficas que tratam do tema, temos a possibilidade interpretá-lo, de certo, como um ano não monolítico de consequências amplamente variadas. Assim, muitas evidências mostram que ele não é um ano homogêneo e sim controverso, no qual as transformações passadas por cada país ou região foram vivenciadas de modo bastante diverso. O mosaico de lutas políticas e rupturas culturais, articulado principalmente através dos meios de comunicação em fins dos anos 1960, permite vislumbrar um grande intercâmbio de influências, não suficiente, porém, para a homogeneização dos movimentos em termos de demandas que a memória social sobre o período tende a recuperar.

Dentro deste complexo emaranhado de movimentos, acontecimentos e processos que saltaram aos olhos em 1968, podemos observar o que chamaríamos de uma primeira vertente: a da reinteração das lutas de libertação nacional. A constantemente televisionada Guerra do Vietnã (1955-1975) pode, nesta vertente, ser entendida como grande símbolo do movimento de descolonização sob o contexto da Guerra Fria, (1945-1991), exemplo objetivo das disputas políticas e ideológicas da segunda metade do século XX. Segundo, Eric Hobsbawm:

Contudo, economia à parte, dois acontecimentos inter-relacionados pareciam então alterar o equilíbrio das duas superpotências. O primeiro era a presumida derrota e desestabilização nos EUA, quando esse país se lançou numa nova grande guerra. A Guerra do Vietnã desmoralizou e dividiu a nação, em meio a cenas televisivas de motins e manifestações contra a guerra; destruiu um presidente americano; levou a uma derrota e retirada universalmente prevista após dez anos (1965-75); e, o que interessa mais, demonstrou o isolamento dos EUA. Pois nenhum de seus aliados europeus mandou sequer contingentes nominais de tropas para lutar junto à suas forças. Por que os EUA foram se envolver numa guerra condenada, a qual seus aliados, os neutros e até a URSS os tinha avisado,* é quase impossível compreender, a não ser como parte daquela densa nuvem de incompreensão, confusão e paranoia dentro da qual os principais atores da Guerra Fria tateavam o caminho (HOBSBAWN, 1995, p. 241). 
Também na África, lutas de povos oprimidos envolvendo guerrilhas se encaixam dentro da vertente das lutas de libertação nacional que se processavam. Zimbábue, Namíbia, Angola, Guiné-Bissau e Moçambique são exemplos dos movimentos que avançavam contra o imperialismo naquele ano (REIS FILHO, 2008, p. 40 e 41).

A segunda vertente dos processos e movimentos de contestação social que se entrecruzam em 1968 é a de questionamento dos modelos chamados de Socialismo Real. Na Polônia, estudantes enfrentaram, nas ruas de Varsóvia, a repressão do regime ao marcharem em passeatas reivindicando o fim da censura, a democratização das universidades, a libertação de presos e a revogação de punições. Na Iugoslávia, a partir da Universidade de Belgrado e alcançando outras cidades, estudantes fizeram ocupações e passeatas cobrando bolsas de estudos, um estatuto para residentes universitários, demissão de indivíduos ligados à vigilância e à censura, fim da violência policial e fim do controle do Partido Comunista na educação e na cultura. (REIS FILHO, 2008, p. 48 e 49). Na Tchecoslováquia, 1968 começaria sob uma perspectiva de mudança em seu modelo socialista. Esse conjunto de medidas políticas e econômicas caracterizou o que se passou a chamar de Primavera de Praga (REIS FILHO, 2008, pp.: 48 e 49). A União Soviética lideraria uma campanha contra o movimento e comandariam os países do Pacto de Varsóvia na invasão da Tchecoslováquia (REIS FILHO, 2008, pp.: 50 e 51). Na China, o controverso processo da chamada Revolução Cultural ainda tentava continuar seu caminho. Uma série de reformas nos campos da educação, das relações de trabalho e das instituições, iniciadas em 1965, davam sinais de esgotamento ao chegar em 1968 (REIS FILHO, 2008, p. 51-52).

Outra vertente, em uma terceira perspectiva, trata dos movimentos de contestação social que, em 1968, atingiram as democracias liberais dos Estados Unidos da América e da Europa Ocidental. Os norte-americanos passariam por agitações que colocavam em xeque questões fundamentais para os rumos daquela sociedade, como a luta dos movimentos negros pela afirmação da igualdade de direitos civis. Neste mesmo período, muitos estudantes revoltos contra as convocações para lutar no Vietnã ocuparam pelo menos cinco universidades e enfrentaram policiais nas manifestações de rua que alcançaram mais de 100 mil pessoas, em dezessete cidades (REIS FILHO, 2008, p. 41-42). Ao formar organizações próprias, os militantes dos movimentos homossexuais reivindicavam liberdade e denunciavam a hipocrisia e o preconceito social. Ao mesmo tempo, as militantes feministas questionavam as desigualdades em relação aos homens no campo profissional e nas tarefas do cotidiano, 
revoltavam-se contra o machismo e pregavam a liberação sexual, em espaços privados e também nas manifestações de rua. (REIS FILHO, 2008, p. 43).

$\mathrm{Na}$ Europa Ocidental, o movimento estudantil explodia em diversas universidades. $\mathrm{Na}$ Bélgica, o movimento dos estudantes flamengos protestava contra o domínio valão e contra a estrutura educacional autoritária e obsoleta. Na Espanha, o movimento dos estudantes se chocava com a força policial em passeatas que questionavam a proposta do governo de enquadramento de suas entidades representativas estudantis. Já na Inglaterra, os protestos estudantis questionavam os currículos e métodos de ensino e o apoio à intervenção militar estadunidense no Vietnã. Da mesma forma, na Suécia os estudantes foram às ruas para protestar contra tal guerra imperialista no sudeste asiático (REIS FILHO, 2008, p. 44). Na Itália, desde janeiro de 1968, os estudantes iniciaram uma onda de passeatas e ocupações que se espalharam por diversas cidades que se somou a um ciclo de greves operárias que mobilizou mais de 12 mil trabalhadores (REIS FILHO, 2008, p. 44 e 45). E na Alemanha, a Liga dos Estudantes Socialistas, organizaria diversas manifestações contra o modelo autoritário das universidades e contra a Guerra do Vietnã (REIS FILHO, 2008, p. 44). Tais enfrentamentos, segundo algumas interpretações, abririam espaço para o questionamento da juventude ao passado nazista e seus resquícios ainda presentes na sociedade alemã (HAUG, 1999, p. 28-29).

$\mathrm{Na}$ França, desde o início do ano, a partir da Universidade de Nanterre, se demonstrou o quanto um mal estar estudantil pode se desdobrar numa crise nacional de proporções inimagináveis a princípio. Uma série de conflitos envolveriam estudantes, como manifestações contra expulsões de alunos, boicote de provas, textos questionando o ensino, comícios e ocupações (COHN-BENDIT, 1968, p. 47). No entanto, a situação se agravaria com a disputa sobre as mudanças do estatuto da cidade universitária - questão fundamental que envolvia a vida cotidiana, pois os estudantes queriam o direito de receber pessoas do sexo oposto em seus quartos, poder discutir política, economia, cultura. Além da questão da cidade universitária, os estudantes reivindicavam a reformulação dos currículos e dos métodos de ensino, faziam duras críticas ao autoritarismo e ainda se somavam as manifestações de repúdio a Guerra do Vietnã (REIS FILHO, 2008, p. 45). A série de conflitos levou à intervenção policial, que fechou a Nanterre e a Universidade de Sorbonne, que sairia em seu auxílio, realizando um comício contra o autoritarismo. Os protestos estudantis alcançaram outras províncias do país. Paralelamente, os operários, junto a outros segmentos sociais, entrariam no processo com uma greve geral de 10 milhões de indivíduos e com diversas 
ocupações de fábricas. A repressão tendeu assim a refluir e o Estado abriu o processo de negociações. De Gaulle convocaria novas eleições e garantiria acordos favoráveis para os operários, puxando, assim, o movimento para as vias institucionais. A derrota dos candidatos progressistas faria refluir o movimento nas suas bases de abrangência nacional deixando os estudantes isolados para uma revolução de fato, embora permanecessem categoricamente ativos (REIS FILHO, 2008, p. 45-47).

Entre os movimentos de contestação social de 1968 pelo mundo, a vertente dos que atingiram as democracias liberais dos Estados Unidos da América e da Europa Ocidental, teve de fato uma grande interseção com as transformações comportamentais. Nestas regiões, a música, o teatro e o cinema reformulariam suas linguagens, códigos e propostas, traduzindo inquietações de suas juventudes, artistas e intelectuais (REIS FILHO, 2008, p. 52-53).

Já a quarta vertente dos movimentos de contestação social de 1968, foram as lutas de questionamento do poder político que se espalharam por muitos países da América Latina. Tais lutas, protagonizadas pelos estudantes, tiveram varias interseções com a luta revolucionária em organizações armadas de esquerda. Neste contexto de disputas, as questões culturais que incidiam sob os comportamentos também apareceram. Porém, estavam de acordo com realidades domésticas muito específicas que demandam de investigação historiográfica. Segundo Maria Paula Araújo:

Esquerdas, juventudes e radicalidade política estiveram fortemente vinculadas e, mais do que isso, deram uma marca inequívoca às décadas de 1960 e 1970 na América Latina. Em boa parte da região, essa conjugação se expressou na proposta política da luta armada. Muitos foram os países latino-americanos que, nas décadas de 1960, 1970 e até de 1980, experimentaram a luta armada com o objetivo da revolução socialista: Venezuela, Guatemala, Peru, Colômbia, Nicarágua, Uruguai, Brasil e Argentina (ARAUJO, 2008, p. 247-248).

O saldo da repressão a greves e manifestações na Venezuela, foi de quatro estudantes mortos. Também na Argentina, na capital Buenos Aires e na cidade de La Plata, aconteceram enfrentamentos entre estudantes e policiais. No Peru, na Bolívia, no Chile, na Guatemala e em São Domingos, os movimentos estudantis estiveram nas ruas. No Uruguai, estudantes e trabalhadores estavam presentes em 1968, sendo organizadas duas greves gerais de um dia. Enquanto no México, o processo de luta dos estudantes pela autonomia educacional da universidade e pelo fim da repressão ao movimento estudantil acabaria em um massacre brutal de 500 estudantes em uma passeata, seguindo-se de milhares de prisões e censura (REIS FILHO, 2008, p. 47-48). 
O Brasil, neste mesmo contexto, foi palco de um intenso processo de contestação da ordem vigente, estabelecida pela ditadura civil-militar, há quatro anos instaurada. Neste curto percurso, o regime passou por um gradual processo de radicalização que culminaria no fim de 1968 com o "Ato Institucional n". 5", legalizando o aparato repressivo do Estado. As principais metrópoles do país conviveriam cotidianamente, com conflitos entre o poder repressivo e parte da sociedade civil. O Movimento Estudantil, nesta conjuntura, assumiu grande importância representando uma forte voz contrária ao governo ditatorial. Posteriormente, com seu enfraquecimento, acabara por ter uma parcela dos seus militantes optando por engrossar as fileiras do combate armado à ditadura civil-militar, através da filiação a organizações revolucionárias de esquerda (REIS FILHO, 1990). Essas frentes de luta obtiveram um crescimento vertiginoso em número de combatentes e atividades armadas, no decorrer imediato do período. Muitos de seus militantes, que antes atuavam simultaneamente também no movimento estudantil, agora se dedicavam mais ou exclusivamente às organizações, além dos novos quadros que a elas se integravam.

No Brasil, segundo Marcelo Ridenti, as especificidades locais estiveram acima das influências internacionais e da identidade contestadora partilhada com movimentos de outros países. Porém, ainda que o movimento estudantil brasileiro tenha uma dinâmica de lutas particulares, não se pode negar uma grande nuance de condições materiais comuns com outras nações. Tais condições também atingiam de alguma forma esta parcela da juventude, criando uma relativa sintonia em termos de demandas com outros movimentos de jovens estudantes pelo mundo. Questões similares como acelerados processos de crescimento das metrópoles, formação de modos de vida urbana, uso da pílula anticoncepcional, aumento da massificação cultural através do desenvolvimento dos meios de comunicação, expansão numérica das classes médias, aumento das quantidades de jovens entre as populações, crescimento do acesso às universidades e não inclusão dos jovens nos modelos políticos representativos tradicionais. Tais perspectivas eram comuns a muitas sociedades e impulsionaram mudanças comportamentais possibilitando a multiplicação de movimentos contestatórios protagonizados por jovens. No entanto, não são elas suficientes para explicar a avalanche de movimentos que atravessaram 1968 (RIDENTE, 1999 p. 55-56).

Desta forma, a conjuntura de enfrentamento e radicalização que atravessa o ano de 1968 no Brasil, tanto pelas formas de repressão do Estado, quanto pelos métodos de organização de seus opositores, nos indicam que a principal demanda interna daquela pequena, mas considerável parcela da juventude brasileira envolvida nas agitações sociais, era 
a luta contra a ditadura civil-militar. Mesmo assim, a memória das grandes transformações culturais e comportamentais aparece neste contexto de forma bastante forte. Ela por sua vez não é de todo falsa, mas isso não impede que certas operações realizadas no intuito de recordá-las recriem situações de evidências frágeis. Inclusive, é importante ressaltar que certas transformações que alcançaram o Brasil foram paralelas aos movimentos políticos de esquerda. A questão do jovem como ator social, o uso da pílula anticoncepcional, as questões sobre o amor entre homens e mulheres, são exemplos de relações que foram sendo estabelecidas paralelamente a movimentos políticos. Assim, podemos interpretar que as transformações nos costumes estariam ligadas a questões mais gerais em curso na sociedade capitalista moderna, mas que de todo modo permanecem sendo políticas no sentido mais estrito do termo.

Porem, muitos depoimentos de militantes da luta contra a ditadura civil-militar no Brasil em 1968, assim como muitas obras midiáticas sobre o tema, tendem a recuperar a memória das transformações dos costumes, comportamentos, sexualidades e relações de gênero, como se estas questões tivessem sido colocadas pelo movimento político. Estas operações memorialísticas tende a supervalorizar o lado revolucionário também em termos comportamentais do movimento político. Tais atores não partem do zero para reconstruírem seus passados individuais neste vasto e complexo contexto coletivo. Mas demandas do presente acabam por influenciar a reconstrução de vivências. No entanto, se nota que havia em curso um processo de questionamento dos saberes, nas relações entre o velho e o novo. Assim, o ano de 1968 aparece como uma dobradiça entre as continuidades e rupturas que começam a vir à tona durante a década de 1960, abrindo a necessidade de se investigar as implicações de tal memória e os usos que dela se estabelecem (TODOROV, 2004, p. 25). Uma vez que a memória dos movimentos de contestação social de 1968 está diretamente atrelada à traumática memória da resistência contra a ditadura civil militar brasileira por alguns jovens de uma geração (SIRINNELI, 1996, p. 134-137).

Daniel Aarão Reis Filho propõe que a lei de Anistia promulgada no ano de 1979, abriria um processo de conciliação social após vários anos de ditadura civil-militar. É nesse período que, segundo o autor, se constrói o mito da veementemente resistência da sociedade brasileira frente à ditadura, sustentado no argumento que o regime sobreviveu apenas através da repressão e da manipulação (REIS FILHO, 1997, p. 34-35). Neste sentido, Denise Rollemberg, de forma bastante apropriada, utiliza o conceito de "zona cinzenta", elaborado por Pierre Laborie, para analisar a sociedade brasileira nestas duas décadas de ditadura. A 
historiadora identifica, além das posições a favor e contrarias ao regime autoritário, as ambivalências e as omissões que viabilizaram o longo período dos militares no poder, com a perspectiva de problematizar a memória da ampla resistência da sociedade brasileira a ditadura civil-militar (ROLLEMBERG, 2010, p. 4 -5).

Segundo Rollemberg é possível observar três linhas de interpretação historiográfica para o período da ditadura civil-militar brasileira. Uma que vê o regime garantindo sua manutenção apenas através da coerção e que estava em pleno embate com os movimentos sociais, tendo sua derrocada total junto à sociedade, com a crise do "milagre econômico". Linha interpretativa que teria prevalecido, segundo a autora na memória coletiva da sociedade brasileira e que, nesse sentido, se desdobraria na lógica da ampla resistência da sociedade ao regime. Outra interpretação propõe a alternância das linhas "dura e moderada" do governo militar, regime que ruiria pelas contradições internas pungentes de forma incontrolável nos últimos anos de vigência. Linha interpretativa que também abre espaço para a lógica da ampla resistência da sociedade ao regime. E a última, que considera moderadamente focos de resistência social, mas que entende que havia projetos rivais em disputa entre os militares, mas que no percurso não há uma perda de controle do processo pelos militares. E que a própria transição para a democracia se dá no ritmo imposto por eles, dotado de grandes continuidades, como os governos civis que se seguiram e a própria lei de anistia (ROLLEMBERG, 2010, p. 2-4).

A perspectiva da memória coletiva que se estabeleceu em relação à ditadura civilmilitar brasileira, baseada na linha interpretativa de que a sociedade teria resistido amplamente a ela possibilitando desta forma a conciliação social, dá margem a outros desdobramentos da memória. Desta forma a memória de 1968, momento pontual dentro desse contexto específico de ditadura, também está em questão. Se a memória permite afirmar que todos resistiram à ditadura civil-militar, por que não afirmar que o movimento de 1968 foi extenso em termos nacionais e internacionais? Pois a partir deste viés pode-se afirmar que a mudança de comportamentos e costumes, como em outros países, é tributária essencialmente deste movimento. Por isso, nutrir essa memória reforça a lógica da insubordinação da sociedade brasileira frente ao regime ditatorial e conservador. Afinal, a ideia da ampla transformação também nas bases comportamentais, combina bem mais com a tese de resistência social à ditadura civil-militar brasileira do que a perspectiva de que os valores e práticas dessa bandeira de luta tenham adentrado em nosso país, através da dinâmica própria 
do capitalismo, que soube muito bem se reapropriar de tais demandas (REIS FILHO, 2008, p. $10)$.

De tal modo, em uma análise mais aprofundada da questão, podemos perceber que não há contradição entre a memória da sociedade brasileira que se reivindica como resistente à ditadura civil-militar, com a memória da militância brasileira enquanto parte do amplo grupo da geração 68 e transpõe de forma generalizante a bandeira da mudança de comportamentos e costumes para sua realidade, naquele período. Pelo contrário, essa memória se legitima na medida em que tais mudanças se tornam então demandas sociais da época, transformada agora através do olhar do presente, como fortemente reivindicada naquele movimento. Assim, é nessa atualização do passado ditatorial a partir do presente que a sociedade brasileira se encontra. É sob essa perspectiva que se observa e se questiona os "usos do passado" (TODOROV, 2004, p. 15-18) que andam sendo processados. É dentro desse panorama que 1968, em nosso ponto de vista, tem de ser discutido, na medida em que se insere no contexto dos ainda controversos anos da ditadura civil-militar no Brasil.

Individual, porém construída coletivamente, a memória comporta-se, cotidianamente, através de demandas específicas de cada realidade (POLLAK, 1989, p. 02). O ato lembrar é condicionado por critérios que imprimem uma seletividade. E desta maneira haveria, a utilização de critérios, conscientes ou não, para as lembranças que serão utilizadas para fins específicos, dessa lembrança selecionada a partir da demanda do presente (TODOROV, 2004, p. 17). Alguns dos indivíduos ícones do movimento de contestação social e política, ocorridos no Brasil em 1968, figuram hoje em inúmeras esferas do poder nacional e parte de seu status ainda está diretamente ligada à sua atuação política no período. Paralelamente, a maioria dos indivíduos que participaram do movimento e permaneceram em relativo anonimato, muitas vezes, recuperam aquele momento como parte integrante de sua história pessoal. Nos dois casos, considerando as devidas proporções e as intenções dos usos deste passado (TODOROV, 2004, p. 17), muitos se referem aos acontecimentos acreditando alcançar a mais completa veracidade e sinceridade e, de forma alguma, parecem considerar o condicionamento do presente sobre suas palavras (ROUSSO, 1996, p. 98). Neste contexto, muitas produções midiáticas reatualizaram tais reminiscências no bojo do processo de conciliação social, tendo como pano de fundo a ainda vigente lei de anistia promulgada em 1979 (REIS FILHO, 1990).

Considerando as repercussões atuais que o ano de 1968 ainda possui sobre os indivíduos e a sociedade como um todo, os conceitos de geração e gênero auxiliarão na 
tentativa de uma análise aprofundada que permita pontuar o plano em que se encontrava a questão dos costumes e dos comportamentos dentro do debate político realizado pelos diferentes segmentos sociais que compuseram o movimento brasileiro. Segundo JeanFrançois Sirinnelli, a noção de "geração" figura em nosso cotidiano para além de uma característica biológica, sendo detentora de fortes perspectivas sociais e culturais. Ela é um parâmetro significativo de como as civilizações se autodividem no tempo (SIRINNELI, 1996, p. 131-132). O autor propõe que a consolidação de uma geração está ligada essencialmente à aquisição de "existência autônoma e uma identidade - ambas geralmente determinadas por um acontecimento inaugurador" (SIRINNELI, 1996, p. 133-137). Este ainda coloca que além dos contornos dados à geração por tal acontecimento, se faz presente também os sentimentos de "autorrepresentação" e "autoproclamação". O forte sentimento de fazer parte de um grupo identitário que se diferencia dos demais. (SIRINNELI, 1996, p. 133).

No que se refere aos debates de "gênero" fundamentais na tentativa de compreender os limites enfrentados pela geração 68 brasileira relativos às transformações comportamentais, Joan Scott, em seu artigo "Gênero: uma categoria útil de análise histórica", considerado de grande relevância para os estudos sobre o conceito, propõe a seguinte definição:

\footnotetext{
Minha definição de gênero tem duas partes e várias sub-partes. Elas são ligadas entre si, mas deveriam ser analiticamente distintas. O núcleo essencial da definição baseia-se na conexão integral entre duas proposições: o gênero é um elemento constitutivo de relações sociais baseado nas diferenças percebidas entre os sexos, e o gênero é uma forma primeira de significar as relações de poder (SCOTT, 1991, p. 21).
}

Para além da definição de Scott, o desenvolvimento dos estudos que se debruçam sobre a categoria gênero como instrumento de análise das relações sociais, tem permitido a construção de arcabouços teóricos que começam a refinar a própria categoria com a finalidade de dar conta de novas problemáticas, visto que o entendimento exclusivamente binário dos gêneros, com as noções sexuais de masculino e feminino, não consegue esgotar. Assim, emergem de forma significativa neste contexto bibliográfico os pensamentos de Judith Butler, que analisa as falas científicas que constituíram o discurso da dualidade sexual. (BUTTLER, 2003, p.24). Consequentemente a essa desconstrução da binariedade sexual enquanto natural, ela nos leva a entender o sexo como uma construção social e o gênero não como significado cultural das diferenças sexuais dadas pela natureza, mas como portador de relações de poder, disfarçadas pelo discurso da essência biológica. Os gêneros, nessa perspectiva, são performances, construções intencionais de significado social de que o sexo então é derivado (SOIHET e PEDRO, 2007, p. 293-294). 
Desse modo, direcionamos nosso olhar aos tópicos da sexualidade e das relações de gênero, tendo em vista compreender a ideia que se construiu sobre a chamada "revolução sexual" e como essa perspectiva se desenvolveu com o passar dos anos, de acordo com as condições que foram e são hoje presentes. Pois, em função da recorrente afirmação das transformações nos padrões comportamentais como principal herança deixada por 1968 (REIS FILHO, 2008, p. 53), pretende-se mapear os paralelos estabelecidos, através do ato de rememorar, com os demais países que passaram por agitações sociais, a fim de questionar os usos do passado que derivam desta complexa problemática. Como por exemplo, a conciliação social das classes médias que apoiaram a ditadura civil-militar com alguns grupos de jovens da geração 68 brasileira que através do movimento de luta armada, tentaram derrubar o regime e promover a revolução socialista. Estudantes com disposição combativa e transformadora que muitos veículos de comunicação tentam silenciar através da exacerbada exaltação das mudanças comportamentais e da desvinculação do alcance de tais rupturas do ambiente de lutas políticas que se processavam em paralelo no período. Perspectiva memorialística presente em obras midiáticas famosas como, por exemplo, no livro "1968: o ano que não terminou" (1988), na serie Anos Rebeldes (1992) e no filme "O que é isso, companheiro?" (1997). Ao mesmo tempo essa forma de uso do passado contribui para silenciar os efeitos do terrorismo promovido pelo Estado brasileiro contra estes jovens opositores e alguns outros grupos, por cerca de duas décadas.

De acordo com a corrente de pensamento substantivamente representada por Judith Butler podemos submeter outras sexualidades ao cenário complexos das relações de gênero (BUTLER, 2003, p. 24), uma vez que o sexo, a partir de tal referência, é uma construção social a partir dos gêneros. A homossexualidade, em sua diversidade como prática da sexualidade humana, passa a ser entendida como inscrita dentro das relações de gênero, que se multiplicam constituindo novas variações para a formação das identidades sociais. E por sua vez, passam a ser analisada através das relações de poder que cotidianamente se estabelecem. Neste sentido, também participam do processo de constituição da memória social. Inclusive no que nos interessa neste estudo: o desenvolvimento da memória dos movimentos de contestação da ordem vigente em 1968 e seus desdobramentos enquanto processo no que tange as transformações dos costumes, comportamentos, relações de gênero e sexualidades.

Neste sentido, a trajetória de Herbert Daniel, sendo compreendida a partir do que propõe Pierre Bourdieu, como dotada de incessantes transformações e só sendo possível de 
ser entendida a partir da reconstrução do contexto - "superfície social"- onde se desenrola (BOURDIEU, 1996, p. 184-185), nos revela uma série de nuances sobre as normas comportamentais, seu funcionamento efetivo e as possíveis brechas de negociação (LEVI, 1996, p. 179-180), dentro deste segmento específico da geração 68 brasileira: o das organizações armadas revolucionárias de esquerda. Tanto durante o período de clandestinidade, mas também no exílio. Sendo a luta armada, uma fração relevante, em termos qualitativos, da juventude evolvida politicamente no processo de contestação da ordem, nos anos que antecederam e principalmente que se seguiram a 1968.

Segundo Sabina Loriga é a partir de movimentos individuais que se rompem as homogeneidades, revelando os conflitos, inércias, ineficácias e incoerências entre as diferentes normas sociais (LORIGA, 1998, p. 249). Assim Daniel, como outros militantes, só experimentaria abertamente a homossexualidade, na condição de exilado, o que por sua vez, não o livrou de críticas e acusações posteriores. Tal conduta permanecia como inaceitável, dentro da organização que militou, de acordo com seus reconhecidos códigos morais (DANIEL, 1982), mesmo após uma década passada, do chamado advento da "revolução sexual" e do início dos questionamentos mais expressivos as relações de gênero, em alguns países do continente europeu.

Nascido em 14 de dezembro de 1946 na capital mineira de Belo Horizonte, Herbert Eustáquio de Carvalho, começaria sua militância política após ingressar na Universidade Federal de Minas Gerais em 1964. O jovem aluno do curso de Medicina inicialmente se ligaria ao movimento estudantil chegando à vice-presidente do Diretório Central dos Estudantes. Entre 1967 e 1969, ele passaria pelos grupos Organização Revolucionária Marxista-Político Operária (ORM-Polop), Comando de Libertação Nacional (COLINA), Vanguarda Armada Revolucionária (Var-Palmares) e por fim a Vanguarda Popular Revolucionária (VPR). Nesta última organização, Daniel, um dos codinomes pelo qual passou a ser chamado na luta revolucionária, realizou sua primeira de muitas ações armadas, vindo a ser reconhecido como um militante combativo e preparado, digno de funções de grande confiança (DANIEL, 1982, p. 26-27, 51-52).

A partir da grande responsabilidade que pesava sob as organizações de vanguarda, impunha-se ao militante uma conduta exemplar a partir de normas de comportamento supostamente dignas de um revolucionário. Ou seja, superando por um lado o reformismo das organizações comunistas tradicionais, o revisionismo desagregador da luta revolucionária e os desvios morais característicos da burguesia. Era necessário criar e viver uma moral 
revolucionária enquanto exemplo para a nova sociedade que se pretendia construir (REIS FILHO, 1990, p. 123).

\begin{abstract}
Meus problemas pequeno-burgueses me preocupavam, como tantos empecilhos que eu tivesse para poder me tornar um bom revolucionário. Entre eles a sexualidade, mais explicitamente, a homossexualidade. Desde que comecei a militar, senti que tinha uma opção a fazer: ou eu levaria uma vida sexual regular- e transtornada, secreta e absurda, isto é, puramente "pequeno burguesa", para não dizer "reacionária", ou então faria a revolução. Eu queria fazer a revolução. Conclusão: deveria esquecer minha sexualidade. (DANIEL, 1982, p. 96-97)
\end{abstract}

Herbert Daniel em seu livro "Passagem para o próximo sonho: um possível romance autocrítico", ao contar sua experiência de militância política e exílio expressa de forma veemente o choque de viver abertamente a homossexualidade com as possibilidades de ser um revolucionário de esquerda integrante de uma organização armada. Segundo Daniel, como podemos verificar no trecho acima, a homossexualidade configuraria um grave problema em sua prática revolucionária. Pois, a revolução exigia do militante uma postura sexual regular e qualquer questionamento sobre a questão, seriam considerados como despropositados pela organização. $\mathrm{O}$ autor coloca que o sexo não era visto de forma geral pelos militantes das organizaçõos revolucionárias como uma questão política, mas sim como uma questão estritamente pessoal. Em particular, a homossexualidade era vista como um desvio pequenoburguês, que no cotidiano da militância junto a seus companheiros de luta armada podia tomar o caráter de grave acusação. Neste sentido, Herbert Daniel afirma ter renunciado à sua sexualidade, não sendo então um problema para os outros. Afirma ele ter assumido um comportamento assexuado que seguia os modelos imaginados de uma classe operária sem desvios sexuais: "Tinha um comportamento exemplar. Nenhuma relação homossexual obscureceu meus dias de militância" (DANIEL, 1982, p. 96-97).

Em muitas de suas obras o autor contou quais eram as margens para a vivência cotidiana das sexualidades e mais especificamente da homossexualidade, dentro das organizações marxista-leninistas revolucionárias por que passou. Em "Meu corpo daria um romance", Daniel também contaria alguns episódios significativos do entendimento e do espaço que o debate possuiu: "Marcelo naquela época ainda não poria em prática sua teoria; continuaria cultivando sua abstinência sexual que tornara "normal" nas contendas da guerrilha" (DANIEL, 1984, p. 36).

Para além das relações sexuais interditadas por uma gama de orientações morais que os guerrilheiros tinham que se enquadrar, havia como consequência também a interdição afetiva; a impossibilidade dos amores adolescentes que afloravam e se desenvolviam na 
transição para a vida adulta. Herbert Daniel, assim como outros jovens militantes das organizações que integrou, evitaram os encontros com os amores fora dos padrões revolucionários. Entre tantos resultados da luta contra o regime ditatorial, são expressivos na narrativa os sentimentos de dúvida, renúncia e solidão. Nesta perspectiva, conta que até sua relação com Cláudio Mesquita, seu cônjuge por mais de 20 anos, também teria sido cerceada pelos valores correntes em sua organização. Valores que, acima de tudo, eram internalizados pelos militantes, sem margem para um debate sobre suas referências, as quais, como já expressado acima, para o autor reproduziam uma lógica "puramente pequeno burguesa", para não dizer "reacionária" (DANIEL, 1982, p. 96). Nas palavras de Daniel:

\begin{abstract}
O meu romance - dito real - continuou, sem que eu fosse Crusoé, numa sexta-feira em que conheci Cláudio. Também numa sexta-feira véspera de carnaval, fugimos da última queda, escapamos. Com Cláudio iria conhecer, iríamos, um diálogo enorme, que durou anos, onde falamos um do outro, contando casos de si mesmos. Descobrimos o sexo. Não que tenhamos nos tocado: durante anos falamos apenas, contávamos nossas experiências com terceiros. Só muito tempo depois de ter conhecido Cláudio que despontou em mim a hipótese de praticar um sexo homossexual - verbalizava, sem reconhecer. A homossexualidade me resolveu angústias, mas não me afastou do exílio, e, sim, me fez conhecer outros (DANIEL, 1982, p. 127).
\end{abstract}

Somente no exílio Herbert Daniel e seu companheiro de vida, Cláudio Mesquita, ou Lauro e Beto, como passaram a se chamar durante a fuga, viveriam o amor. Cláudio e sua família serviram, enquanto simpatizantes, de fachada para o esconderijo de um dos guerrilheiros mais procurados do país. Infelizmente os órgãos de inteligência do regime civilmilitar conseguiram chegar até o aparelho que abrigava Herbert Daniel, após a captura do embaixador suíço. A família de Cláudio Mesquita sofreria bárbaras torturas nas mãos da repressão, mas Beto e Lauro conseguiram escapar. Com a sorte de nunca terem sido presos e torturados, os dois partiram para o exílio.

Embora tenha conhecido a homossexualidade desde o início de sua militância política no Brasil (DANIEL, 1982) - e aqui vivido o revolucionário ano de 1968 e seus desdobramentos - foi somente no exílio que esta seria de fato explorada. E, mesmo assim, a partir de um rompimento com os grupos da esquerda revolucionária que lá tentavam ainda sobreviver. Sobrevivência essa, que segundo Herbert Daniel, não teria modificado os principais problemas internos vivenciados nos tempos de Brasil. Havia, pelo contrário, aumentado os dogmatismos e os sectarismos, e também as resistências às novas questões que continuavam não formuladas. Seu rompimento com alguns grupos de esquerda no exílio se deu a partir do argumento que havia a necessidade de resolver questões políticas, sem espaço como diversas outras, nestes grupos. No caso específico a homossexualidade, encarada por 
Daniel como uma questão política onde se manifestavam uma complexa teia de relações de poder e opressão (DANIEL, 1982).

No segundo momento de seu exílio em Paris, após viver uma temporada com Cláudio em Portugal, Herbert Daniel trabalharia como porteiro em saunas homossexuais e a esta experiência atribui boa parte do seu entendimento sobre o cotidiano da homossexualidade. E também a esta experiência conferiu as reflexões sobre as possibilidades de ser limitado ao gueto que os indivíduos que exercem a homossexualidade são socialmente empurrados (DANIEL, 1982, p. 155).

No Brasil, nos anos de militância, segundo Daniel, existia não somente o receio de sofrer as consequências por ferir os códigos morais de sua organização por conta de sua homossexualidade, mas também a desmoralização do indivíduo e da luta armada:

\begin{abstract}
Anos a fio, carregando a pecha de terrível 'terrorista', um pânico me assombrou: que 'descobrissem' que eu ERA! Vivi um quase pesadelo, pensando que os jornais, que certa vez me classificaram de 'braço direito de Lamarca', poderiam estampar esta manchete assustadora: "Guerrilheiro Bicha". Ou: "O terrorista era um tremendo invertido"... $\mathrm{Na}$ época a gente imaginava que essas coisas eram ofensivas e "taras sexuais" eram reservas (i)morais da Pátria da direita. À esquerda éramos abstratos, voláteis, imunes: o corpo-militante era o corpo de um anjo exterminador de sexo exterminado. Não é por outra razão que eu - e todos!- silenciava. Bicha admissível, só a caladinha (DANIEL, 1982, p. 25-26).
\end{abstract}

Neste trecho, o autor expressa além da moral burguesa proferida pelos jornais da qual temia ser vítima, mas também aspectos da moral vigente e das relações de gênero, que teria vivenciado na organização armada revolucionária de esquerda que principalmente militou. Ambas as posições morais em análise, estão muito distantes de entender a homossexualidade como uma das possibilidades da sexualidade humana, como defende Herbert Daniel, mas sim como um desvio de uma sexualidade natural padrão: a heterossexualidade. No caso da esquerda um desvio típico, entre os diversos vícios, da burguesia. E ainda quando praticada em seu interior, somente possível de forma silenciosa. Ou seja, visões e práticas incongruentes sobre os aspectos da "revolução sexual", que hoje de forma memorialística, é proposta como um processo amplamente generalizado dentre a "geração 68 " de todo o mundo.

Mesmo em seu exílio na Europa, onde os ares de mudança comportamental teriam estremecido as estruturas sociais, Herbert Daniel conta ter enfrentado tanto afastamento silencioso quanto a exclusão lenta, travestida de "aceitação", de seus amigos de militância na medida em que opta por vivenciar abertamente sua homossexualidade (DANIEL, 1982, p. 59). No início do ano de 1979, em Paris, junto à Comissão de Cultura do Comitê Brasil pela 
Anistia, promoveu o debate "Homossexualidade e Política" (DANIEL, 1982, p. 213). Nesta ocasião, Herbert Daniel foi responsável pela condução dos trabalhos que posteriormente lhe renderiam a autoria do documento "Homossexual: defesa de seus interesses?", publicado em maio do mesmo ano, na revista Notas Marginais - $n^{o}$ 3, pelo grupo de mesmo nome. O documento teria sido o primeiro a discutir a homossexualidade dentro das esquerdas brasileiras e lançou as bases fundamentais de suas críticas, que foram posteriormente desenvolvidas em seus livros. Estas críticas partem de análises sobre a modelação do homossexual pelos mecanismos de poder burguês como forma de promover a repressão específica a tal grupo.

Herbert Daniel critica a perspectiva, assumida de forma geral pelas esquerdas, que tratam o homossexual como uma minoria com um interesse de grupo definido. Reproduz, assim, a moral herdada da burguesia e com isso não compreende os mecanismos pelos quais tal classe social, exerce seu poder de modelação sob os sujeitos, estando às esquerdas pouco capacitadas para combatê-la. Ele afirma que a esquerdas se apropriam desta mesma lógica para elaborar seu discurso. Este discurso, por sua vez, faz o autor duvidar de qualquer possibilidade de mudança sobre o olhar social dirigido a homossexualidade:

\footnotetext{
Para a esquerda, a questão da homossexualidade não é a de um grupo, uma minoria social, que pode ser contada como força política na luta contra o capitalismo. $\mathrm{O}$ problema, em seu fundo mesmo, é de compreender a ação do Poder, para melhor poder combatê-lo. Ao falar sobre a homossexualidade, enquanto homossexual, não se faz uma tentativa de introduzir um discurso homossexual na esquerda, MAS UMA CRÍTICA AO DISCURSO HOMOSSEXUAL QUE A ESQUERDA TEM.

Um discurso do "preconceito" - Isto é, uma moralidade herdada da burguesia e que a faz politicamente pouco capacitada a enfrentar e destruir o Poder burguês. Não é um grupo homossexual que deve se responsabilizar por isso. (DANIEL, 1979, p. 9)
}

A promoção do debate foi marcada por grande resistência de grupos que compunham o Comitê Brasil pela Anistia, com argumentos que iam desde "o homossexualismo é uma doença", ou "é resultado da decadência do capitalismo", até sexualidade "não é um assunto diretamente político". Este episódio acabaria por desvelar de forma direta a vasta gama de preconceitos que envolvia a questão da homossexualidade - conduta sexual associada aos desvios morais da burguesia reacionária -, pois envolveu desde o silêncio daqueles que não queriam participar da discussão à censura dos que tentaram impedi-la. Tamanha teria sido a mobilização contrária ao debate que o Comitê Brasil pela Anistia chegaria à beira de um racha e, para evitar a divisão do Comitê, a Comissão de Cultura tomaria a iniciativa de realizá-lo de forma autônoma, em uma sala da Casa Brasil na Cidade Universitária (DANIEL, 1982, p. 214-218). 
Sob o prisma dos estudos biográficos na historiografia (LEVI, 1996, p. 182), a trajetória de Herbert Daniel, nos permite a interpretação que eram objetivamente restritos os limites para a vivência cotidiana da homossexualidade nas organizações marxista- leninistas armadas que pretendiam derrubar a ditadura-civil militar e promover a revolução socialista como vanguarda da classe operária. Tais questões de foco comportamental estavam fora de qualquer perspectiva de debate político em organizações como a VPR. No entanto, não podemos ser anacrônicos em relação à prioridade e o sentido que se dava às questões comportamentais em meio ao contexto onde se acredita estar vivendo um processo revolucionário em curso. Processo que implicava em uma luta de morte com um mecanismo cada vez mais eficiente de terrorismo de Estado. Os órgãos de repressão civis e militares utilizavam-se da censura, da perseguição política, da tortura e do assassinato de forma cada vez mais sistemática contra seus opositores. O AI-5 de 13 de dezembro de 1968 garantiria a uma parcela politicamente relevante da geração 68 brasileira cicatrizes profundas e lembranças amargas. Assim, o contexto dos jovens que viveram a luta armada compreendia sobreviver e ao mesmo tempo fazer a revolução.

Assim o próprio Herbert Daniel deixa claro que entendia sua opção pela renúncia de sua sexualidade enquanto necessidade da luta. "Eu queria fazer a revolução. Conclusão: deveria esquecer minha sexualidade." "Mais que isto: eu era feliz em Ribeira porque não me sentia reprimido. Sentia, como todos deviam sentir, que a ausência de sexo era uma necessidade da luta..." (DANIEL, 1982, p. 97 e 221) Pois é necessário que se pense a importância do exílio de 7 anos na Europa para que Herbert Daniel iniciasse suas críticas as relações de poder que envolvem as sexualidades em um nível essencial das relações sociais. Críticas que nos indicam, em nossa análise de quase 50 anos depois, o quanto era restrito espaço estabelecido para os debates que hoje classificamos como relações de gênero. Mas que, em 1968, no Brasil significavam no pensamento de muitos militantes e na lógica de muitas organizações armadas, debates que poderiam promover a desagregação em torna da luta pela derrubada da ditadura e pela revolução socialista.

Neste sentido, é de suma importância entender melhor o conjunto de experiências transformadoras que os exílios proporcionaram para a geração 68 brasileira (ROLLEMBERG, 1999, p. 132). Ao mesmo tempo, é importante retomar a análise que Rachel Soihet faz da proposição de Thompson, para entender a importância da experiência na aquisição da consciência de gênero que gradualmente se formou entre as mulheres exiladas. Segundo Soihet, é na luta pela revolução política no Brasil e por seus desdobramentos no exílio que 
muitas mulheres perceberam as posições subalternas que eram colocadas pelos seus companheiros de vida e militância e, a partir de tal percepção, passam forçar novos debates sobre as relações interpessoais e afetivas no âmbito do político (SOIHET, 2012, p. 35-37). Desta forma, como indica seus escritos iniciados no final da década de 1970, o contraste de experiências vividas durante 7 anos de militância revolucionária no Brasil e 7 anos de vida no exílio, iram representar um pungente processo de aquisição de consciência de gênero para Herbert Daniel.

Também em seu livro, Herbert Daniel conta o episódio da recusa feita pelo Comitê Brasil pela Anistia (CBA) em proceder à leitura de sua carta de protesto no congresso realizado no final de 1979. A carta denunciava os limites da Lei de Anistia promulgada em 28 de agosto de 1979, que não beneficiava alguns exilados que só poderiam regressar ao Brasil após prescreverem suas penas. Ele iria ouvir várias justificativas, pouco convincentes, dos motivos pelos quais sua carta não teve espaço no congresso. Entre suas tentativas de torná-la pública enviou, então, o texto à mãe do cartunista Henfil e do sociólogo, ex- exilado Herbert de Souza. Henfil foi quem primeiro divulgou a carta em sua coluna de jornal. Em março de 1980 o jornal "O Lampião da Esquina”, publicaria na íntegra a carta. Incluindo uma nota explicativa, caminho pelo qual Daniel veio saber dos reais motivos de sua carta ter sido cerceada junta ao CBA no final de 1979 (DANIEL, 1982). Segundo o jornal "o representante do CBA Comitê Brasileiro pela Anistia do Ceará, cujo nome nem merece ser citado, recusouse a lê-lo porque, segundo ele, o signatário é apenas uma bicha." (SILVA, 1980, p.10)

Este trecho que esclarece a questão para Herbert Daniel demonstra por outro lado que, embora fosse conhecido que o militante da combativa e atuante Vanguarda Popular Revolucionária tenha participado como liderança de várias ações armadas contra o regime ditatorial brasileiro - como a captura do embaixador alemão Ehrenfried Anton Theodor Ludwig Von Holleben em 1970, que libertou 40 presos políticos e do embaixador suíço Giovanni Bucher, ao lado de Carlos Lamarca, libertando 70 presos políticos -, sua posição sobre os limites da anistia pelos quais era diretamente atingido, não eram relevantes para a CBA, em função de suas práticas e identidade sexual. Perspectiva essa que fica claramente colocada quando um membro do comitê, sem nenhuma repreensão relevante que garantisse a leitura da carta de denúncia do exilado no congresso baiano, o ofende diretamente baseado em suas concepções de gênero homofóbicas e machistas, largamente disseminadas na sociedade brasileira. Inclusive, o ocorrido é uma demonstração de como tais concepções ainda eram muitíssimo presentes entre os adultos que haviam sido os jovens de esquerda em 1968, e que 
naquele momento lidavam também com as consequências do processo exílio e anistia. E assim, Herbert Daniel, mais uma vez comprova o exílio político da homossexualidade dentro das esquerdas brasileiras. Sobre o ocorrido comenta:

\begin{abstract}
Algum tempo depois tive uma resposta parcial a tais questões. Recebi o Lampião que, num admirável gesto de solidariedade, publicou na íntegra a carta. Apresentoua comentando um incidente no Congresso do CBA - do qual só tomei conhecimento pelo jornal. Um dos presentes, delegado do Ceará (que pena, verdes mares que brilhas!), opusera-se à leitura da minha carta ali por eu era: "simplesmente uma bicha" (sic) (DANIEL, 1982, p. 229).
\end{abstract}

O processo de retorno ao Brasil pode ser interpretado na trajetória de Herbert Daniel, como um momento significativo onde começa a aflorar a consciência de gênero em seu discurso político. Sendo o contexto das experiências vividas entre 1979 e 1981, pontos perceptíveis nas reflexões propostas em seus escritos e livros publicados até 1984.

Como foi verbalmente dito pelo delegado do CBA cearense, a recusa de ler a carta de protesto de Herbert Daniel contra os limites da lei de anistia, residia em muitos o considerarem um sujeito de menor valor em função de sua sexualidade. Ser "simplesmente uma bicha" (DANIEL, 1982, p.229), ainda implicava em um padrão moral desviante para os revolucionários que se propunham a ser. Ao mesmo tempo, a homossexualidade permanecia largamente rechaçada entre as camadas médias da sociedade burguesa, origem da maioria dos militantes que enfrentaram a ditadura civil-militar. (REIS FILHO, 1990, p. 144-172). Como começava a denunciar Herbert Daniel, a moral revolucionária não estava livre de reproduzir ou simplesmente concordar de algum modo com a moral das classes médias da sociedade burguesa. Os militantes de esquerda envolvidos no congresso baiano do CBA, ao verbalizar ou ao silenciar, acabam por contribuir com as opressões que perpassam a luta de classes e continuavam por entender as questões de gênero e sexualidade enquanto fora da esfera política. Não apoiar Herbert Daniel em seu retorno indica ainda um raso alcance no entendimento destes militantes sobre a importância de defender direitos democráticos individuais. O resultado: Daniel é o último exilado, que desejava o retorno imediato, a pisar no Brasil em 1981.

Finalmente em casa, Herbert Daniel manteve diálogo com alguns grupos de ativistas gays. Em 1982, filiou-se ao Partido dos Trabalhadores (PT), trabalhando na campanha e no mandato de deputado estadual do ex-exilado Lizst Vieira, que tinha como marca de ação os debates sobre cultura, ecologia e homossexualidade. Em 1986, ele tentaria a eleição para deputado estadual, associando sua campanha a de Lizst Vieira para deputado federal e do exexilado Fernando Gabeira para governador do Estado do Rio de Janeiro. O slogan no panfleto 
"Somos a maioria" da campanha de Daniel, era representativo de suas perspectivas políticas neste momento: "Não há democracia se ela pára na porta da fábrica, no fundo do prato, ou na beira da cama." Ainda em 1986, fundaria o Partido Verde (PV), junto com outros dissidentes do PT. Por seu novo partido, Daniel se candidataria à presidência da república em 1989. Neste mesmo momento, é diagnosticado com tuberculose ganglionar e descobre ser portador do vírus da AIDS. Mesmo assim, continua sua campanha, sendo o primeiro candidato à presidência do país assumidamente homossexual e soropositivo. Reafirmava desta forma sua militância no debate sobre os temas, evidenciando as opressões derivadas de associações ignorantes e preconceituosas entre a homossexualidade e a AIDS. Com a saúde debilitada pela doença, Herbert Daniel teve de abandonar a candidatura e foi substituído por Fernando Gabeira no pleito presidencial. Em seus últimos anos, ele ainda escreveria alguns livros relativos às questões sociais que envolvem a epidemia e, em 29 de março de 1992, em decorrência de complicações da doença, Herbert Daniel encerraria sua jovem e militante existência aos 45 anos.

Em suma, sob um olhar que pretende analisar o desenvolvimento da memória dos segmentos que compuseram a geração 68 brasileira, a respeito das transformações dos comportamentos e costumes, adotando referenciais teóricos de Joan Scott e Judith Butler no entendimento do conceito de gênero, a trajetória de Herbert Daniel aqui mapeada através de seus escritos assume uma crucial relevância. Tanto pelos testemunhos de suas experiências de militância e exílio, quanto por suas severas críticas aos padrões morais adotados por diversos grupos armados da esquerda brasileira. Mesmo considerando a tentativa de imprimir coerência sob sua própria vida (BOURDIEU, 1996, p. 184-185) e os efeitos condicionantes do presente (ROUSSO, 1996, p. 98) que se encontrava Herbert Daniel no momento que construiu sua narrativa, - período fortemente marcado pelo processo de anistia e as dificuldades do retorno dos exilados ao Brasil em torno de 1979- sua trajetória é significativa e esclarecedora. Segundo Giovanni Levi, a biografia permite a historiografia promover análises aprofundadas sobre os conflitos, classificações, distinções, representações e margens de liberdade que os indivíduos possuem no interior de seus grupos (LEVI, 1996, p. 182). Assim, tal referencial teórico possibilita, a partir da trajetória de Herbert Daniel, o questionamento de uma memória sobre as transformações dos costumes, comportamentos, sexualidade e relações de gênero, que a "geração 68" como um todo e da mesma forma, haveria vivenciado enquanto um uso do passado que silencia a importância das lutas de 
oposição política e revolucionária em contrapartida à exaltação das mudanças comportamentais.

\section{Referências Bibliográficas:}

ARAUJO, Maria Paula. Esquerdas, juventude e radicalidade na América Latina nos anos 1960 e 1970. In. FICO, FERREIRA, ARAUJO, QUADRAT (orgs.): Ditaduras e Democracias na América Latina: balanço histórico e perspectivas. Rio de Janeiro: Ed. FGV, 2008.

BUTLER, Judith. Problemas de gênero. Feminismo e subversão da identidade. Ed. Civilização Brasileira, Rio de Janeiro, 2003.

BOURDIEU, Pierre. "A ilusão biográfica". In: AMADO, J. \& FERREIRA, M. Moraes (orgs.). Usos e Abusos da Historia Oral. Ed. FGV, Rio de Janeiro, 1996.

COHN-BENDIT, D., SAUVAGEOT, J., GEISMAR, A., DUTEUIL, J.-P. A Revolta Estudantil. Editora: Laudes, Rio de Janeiro, 1968.

DANIEL, Herbert. Homossexual: defesa dos interesses? Notas Marginais - $n^{o} 3,1979$.

Meu corpo daria um romance. Ed. Rocco, Rio de Janeiro, 1984.

Passagem para um próximo sonho: um possível romance autocrítico.

Codecri, Rio de Janeiro 1982.

GARCIA, Marco Aurélio. Em busca de 1968. In: GARCIA, M. \& VIEIRA, M. (orgs.). Rebeldes e Contestadores. 1968: Brasil, França e Alemanha. Ed. Fundação Perseu Abramo, São Paulo, 1999.

HAUG, Walfgang Fritz. 1968 na Alemanha. In: GARCIA, Marco Aurélio e VIEIRA, Maria Alice (orgs.). Rebeldes e Contestadores. 1968: Brasil, França e Alemanha. Editora Fundação Perseu Abramo, São Paulo, 1999.

HOBSBAWN, Eric. Era dos extremos: o breve século XX. Ed. Cia das Letras, São Paulo, 1995.

LEVI, Giovanni. Usos da biografia. In: AMADO, J. \& FERREIRA, M. Moraes (orgs.). Usos e Abusos da Historia Oral. Ed. FGV, Rio de Janeiro, 1996.

LORIGA, Sabina. "A biografia como problema". In: Revel, J. Jogos de Escalas. A experiência da microanálise. Rio de Janeiro: Ed. FGV, 1998.

POLLAK, Michel. Memória, Esquecimento, Silêncio. Estudos Históricos, Rio de Janeiro, vol. 2, n. 3, 1989.

REIS FILHO, Daniel Aarão e MORAES, Pedro de. 1968: A Paixão de uma Utopia. Ed. FGV, Rio de Janeiro, 2008. 
"Um passado imprevisível: a construção da memória da esquerda nos anos 60", "Versões e ficções: a luta pela apropriação da memória". In ----- (org.). Versões e ficções. O sequestro da História. São Paulo, Perseu Abramo, 1997.

Brasiliense, 1990 .

A revolução faltou ao encontro: os comunistas no Brasil. São Paulo,

RIDENTI, Marcelo. Breve recapitulação de 1968 no Brasil. In: In: GARCIA, Marco Aurélio e VIEIRA, Maria Alice (orgs.). Rebeldes e Contestadores. 1968: Brasil, França e Alemanha. Editora Fundação Perseu Abramo, São Paulo, 1999.

ROLLEMBERG, Denise. Exílio: entre raízes e radares. Rio de Janeiro, Record, 1999.

As Trincheiras da Memória. A Associação Brasileira de Imprensa e a ditadura (1964-1974). In: Rollemberg, D. \& Quadrat, S (orgs.). A construção social dos regimes autoritários. Legitimidade, consenso e consentimento no Século XX. Vol. 2: Brasil e América Latina. Rio de Janeiro: Civilização Brasileira, 2010.

ROUSSO, Henry. A memória não é mais o que era. In: AMADO, J. \& FERREIRA, M. Moraes (orgs.). Usos e Abusos da Historia Oral. Ed. FGV, Rio de Janeiro, 1996.

SCOTT, Joan. “Gênero: Uma Categoria Útil de Análise Histórica”. Recife, SOS Corpo, 1991.

SILVA, Aguinaldo. Nota introdutória. In: Íntegra da Carta de Herbert Daniel, publicada no "Lampião da Esquina", março de 1980, n² 22, ano 2.

SIRINELLI, Jean-François. A Geração. In: AMADO, J. \& FERREIRA, M. (org.). Usos e Abusos da Historia Oral. Ed. FGV, Rio de Janeiro, 1996.

SOIHET, Rachel. "Mulheres moldando esteticamente suas existências: feminismo como alavanca para uma sociedade mais justa". Projeto História, Vol.45, PUC/SP, 2012.

e PEDRO, J. "A emergência da pesquisa da História das Mulheres e das Relações de Gênero”. Revista Brasileira de História. São Paulo: ANPUH, 2007.

TODOROV, Tzvetan. Los Abusos de la memória. Barcelona Y ediciones, Buenos Aires, 2004.

Recebido em setembro de 2018

Aprovado em novembro de 2018 